\title{
PROBLEM OF GENITAL PROLAPSES AND THEIR CORRECTION BY NONSURGICAL METHODS
}

DOI: 10.36740/WLek202103131

\author{
Kirill V. Chayka, Yulia V. Lavrenuik \\ SHUPYK NATIONAL MEDICAL ACADEMY OF POSTGRADUATE EDUCATION, KYIV, UKRAINE
}

\begin{abstract}
The aim: to determine the most optimal method of genital prolapse correction among the available nonsurgical methods from the perspective of differentiated approach. Materials and methods: using the methods of comparison, analysis and synthesis, we have compiled and processed the world's data from such major search databases as PubMed, EMBASE, Cochrane over the last ten years.

Conclusions: the detection of genital prolapses at an early stage and the early nonsurgical treatment can prevent the disease progression, eliminate the symptoms, especially urinary problems in most patients, and improve the life quality.
\end{abstract}

KEY WORDS: genital prolapse, fractional $\mathrm{CO}_{2}$ laser, hyaluronic acid, platelet rich plasma, cystocele

Wiad Lek. 2021;74(3 p.l):554-557

\section{INTRODUCTION}

Modern medicine aims to improve the life quality, minimize complications and improve the long-term outcomes of various therapies. Today, women's health has a great impact on the life quality of not only the woman but also her partner. Genital prolapse (GP) is a significant problem, as it makes women feel less attractive and undesirable. The complexity of this pathology on the one hand and the age and numerous extragenital diseases on the other exclude the possibility of surgical correction and require conservative treatment.

When choosing among a great number of various methods of conservative treatment of GP described today, there is no clear element of differentiation. At present, there are no common approaches to the management and choice of nonsurgical correction of prolapse and the conditions associated with it, and therefore this issue is perhaps the most controversial in the treatment of GP.

\section{THE AIM}

To determine the most optimal method of mild forms of genital prolapse correction among the available nonsurgical methods from the perspective of differentiated approach.

\section{MATERIALS AND METHODS}

We have obtained world's data from such major search databases as PubMed, EMBASE, Cochrane over the last ten years. The search was performed by the following keywords: genital prolapse, fractional $\mathrm{CO}_{2}$ laser, pelvic floor dysfunction, hyaluronic acid, platelet rich plasma.
Then using the methods of comparison, analysis, synthesis, generalization and scientific abstraction, we analyzed the obtained data in order to determine the most optimal method of prolapse correction among the available techniques taking into account the possibility of a differentiated approach to solving this problem.

\section{REVIEW AND DISCUSSION}

GP is a problem that is complicated by both the woman's unwillingness to discuss it even with the doctor and the inattention to the initial manifestations of the disease by gynecologists and related primary care professionals. If there are symptoms of GP, every fifth woman is at risk of undergoing surgery before the age of 80 . Therefore, from the point of view of the development approaches to the GP nonsurgical correction, the choice of treatment option is determined by a number of factors, including the age, concomitant extragenital pathology, degree of risk of surgery and anesthetic management, degree of prolapse, anatomical and functional changes of the reproductive organs, presence and nature of concomitant gynecological pathology, possibility and necessity of preservation or sometimes restoration of fertility, features of adjacent organs dysfunction. For historical reasons, conservative methods are almost always in the sidelines when doctors have to deal with the issue of GP correction. However, in recent years, these treatment techniques have become increasingly popular. Each of the conservative methods of GP treatment had a long difficult evolutionary way, but as of today they are still of great significance in the correction of such an important medical and social problem as GP. 
In nonsurgical correction of genital prolapses, the following techniques are of the most importance now:

- the use of fractional CO2 laser in patients with GP combined with neurogenic bladder dysfunction [1];

- the use of pessary as a temporary symptomatic treatment option (when surgical treatment is not possible) $[2,3]$;

- the use of such bulking agents as platelet rich plasma and hyaluronic acid preparations;

- electrical stimulation of pelvic floor muscles using anal, vaginal and urethral sensors;

- training the pelvic floor muscles using Kegel exercise.

\section{PLATELET RICH PLASMA (PRP)}

The use of biotechnologies to accelerate soft tissue regeneration has become one of the modern trends in reconstructive medicine. As a result, the possibility of using platelet rich plasma (PRP) is of great interest among the researchers now. The popularity of the technique is explained by the absence of allergic reactions, the simplicity and ease of use, as well as the increasing scope of application, and GP is no exception here.

Platelet rich plasma (PRP) also termed platelet rich growth factors, platelet rich fibrin, platelet concentrate, is essentially a plasma with an increased concentration of platelets [4]. Normally, the number of platelets in the blood is in the range of $150-350$ thousand/ $\mu \mathrm{l}$ and averages 200 thousand/ $\mu \mathrm{l}$. The studies have shown that the clinical effect of platelet rich plasma should be expected if the platelet concentration in it is $1,000,000 / \mu l$. At lower concentrations, the stimulating effect on the regenerative processes in the tissues is not manifested, at the same time, it has not been proven so far that an increase in platelet concentration of more than $1,000,000 / \mu l$ leads to a further acceleration of regeneration. The use of platelet rich plasma in gynecology is recommended in the treatment of the initial presentation of genital prolapses, in particular the isolated manifestations of 1-2 degree cystocele or rectocele, as well as the correction of non-stress urinary incontinence associated with urethral hypermobility, which is one of the possible consequences of genital prolapse [5]. It is also claimed that PRP is effective in regeneration as well as in the injury remodeling phase. The remodeling phase involves the production of type III collagen by fibroblasts [6]. Despite the interest in the method and the obvious widespread use, there is no evidence of randomized clinical trials evaluating the effectiveness of PRP [7]. The presence of plasma clot formation and platelet growth factors in PRP, which provide the healing and remodeling processes of collagen and elastic fibers, is the basis for its use. PRP contains not only growth factors, but also adhesive molecules and cytokines that stimulate repair and anabolic processes in damaged tissues [8]. It is known that platelet-derived growth factor (PDGF), transforming growth factor beta (TGF-b), epithelial growth factor (EGF) and vascular endothelial growth factor (VEGF) are released from alpha-granules.

\section{HYALURONIC ACID PREPARATIONS}

The mechanism of hyaluronic acid gel polymer action when eliminating initial presentation of genital prolapses involves compensation of soft tissue deficiency in the area of defeat due to the increase of their volume, as well as the mechanical compression [9]. The main requirements for modern bulking agents are, first of all, biocompatibility, the absence of inflammatory response and autoimmune systemic reaction, as well as the absence of fibrosis in the injection site. Also, the particles of these substances have to be of sufficient size (diameter not less than 80 microns) so as not to migrate from the injection site and not to disintegrate for some time $[10-11]$. The procedure is less traumatic, relatively cost effective and can be used in the outpatient setting under local anesthesia.

\section{FRACTIONAL CO2 LASER IRRADIATION}

A laser is a source of light, but unlike thermal light sources, lasers have a high degree of monochromaticity, spatial coherence, directionality and polarization of radiation at a considerable intensity and brightness, and can also be tuned over wavelengths and emit light pulses of short duration [12]. Absorption is a key physical process that ensures the effective interaction of laser radiation with biological tissues (Berger N., Eeg P. H., 2006). When absorbed by the tissue, the laser radiation is converted into thermal energy leading to the rapid tissue heating. $\mathrm{CO}_{2}$ laser belongs to lasers that emit wavelength of $10600 \mathrm{~nm}$, and they interact very well even with a small amount of water (10-15\%), which is in the tissues [13]. Numerous studies prove that the use of $\mathrm{CO}_{2}$ laser for the rejuvenation of mucous membranes gives good prognostic results [1, 14-15]. It is believed that neocollagenesis is the cause of long-term improvement, which is to increase tissue density. Heating with laser irradiation leads to the denaturation of collagen, i.e. the destruction of hydrogen bonds in the tertiary helical structure of collagen fibers, and the subsequent formation of a random helix. As soon as a sufficient amount of collagen fiber denaturation occurs, the tissue is immediately tightened, because when heated, the tissue causes inflammatory mediators to initiate the process of tissue repair and stimulates the synthesis of type I and III collagen [16].

Laser treatment for women with dystrophic changes of the vaginal and vulvar mucosa has been developed in the modern world. This technique was approved by the FDA (USA) in 2015 for the treatment of genitourinary syndrome of menopause and vaginal relaxation syndrome [17]. Due to the stimulating effect of thermal laser exposure, the process of producing collagen and elastin is activated in the area where it is required. The action of $\mathrm{CO}_{2}$ laser on the mucous membranes initiates an aseptic inflammation reaction, accompanied by the synthesis of proinflammatory cytokines IL- $1 \beta$ and TNF- $\alpha$ by tissue macrophages, which causes the induction of AP-1 transcription factor and leads to an increase in the amount of fragmented collagen and MMP-degradable. At the recovery stage, fibroblast proliferation, TGF- $\beta$ growth factor transformation, and intercellular matrix renewal are observed due to type I and III neocollagenesis processes. There is also an increase in the secretion of transforming growth factor TGF- $\beta 1$, which 
regulates collagen synthesis and prevents excessive tissue fibrosis [18]. The result is a unique balance between maximum impact efficiency and minimal tissue damage. It is known that when heated the tissue activates the so-called heat shock proteins (HSP). This is one of the fundamental changes occurring at the molecular level, not taking into account changes in the regulation of other molecules, such as transforming growth factor $\beta$ (TGF- $\beta$ ), hyaluronidase and hyaluronic acid [19-21]. Zerbinati et al. in their study also showed that using $\mathrm{CO}_{2}$ laser for photorejuvenation of the vaginal epithelium activates heat shock proteins, increasing glycogen content in the cells of the vaginal epithelium, thereby increasing the thickness of the vaginal epithelium [22]. Some studies showed the activation or induction of TGF- $\beta$ growth factors by laser treatment 2-14 days after irradiation. Growth factors contribute to the synthesis of matrix components, such as fibronectin and collagen, transformation of myofibroblasts, angiogenesis due to the reaction of heat shock [23-25]. Also, one of the important enzymes that catalyze the breakdown of collagen are matrix metalloproteinases (MMPs), which levels increase in the first three days after treatment, reaching a maximum by day 7. There is evidence that MMPs are involved not only in cleavage but also in remodeling of new collagen [26].

Currently, we have sufficient experience of the treatment of various pathological changes in the vulvovaginal area using fractional $\mathrm{CO}_{2}$ laser systems. For vaginal exposure, the following parameters are used: wavelength $10600 \mathrm{~nm}$, tissue power $30 \mathrm{~W}(\max )$, peak power $320 \mathrm{~W}(\max )$, frequency from 5 to $100 \mathrm{~Hz}$, pulse length from 0.2 to $80 \mathrm{~ms}$, and seven-mirror articulated arm for radiation delivery. It is common practice to perform 3 treatment procedures with an interval of 1 month, and then to maintain the achieved effect with a single procedure once per 6-12 months. Complete tissue repair occurs by the 30 th day after $\mathrm{CO}_{2}$ exposure [27]. Laser thermolysis is one of the most important discoveries in laser technologies in the last two decades. The use of this technology for the treatment of genital prolapses in the early stages of their development acts as an incentive to further improvement of this technique. All of the above mentioned methods can be used both as monotherapy and in combination.

\section{CONCLUSIONS}

Having analyzed the main sources of literature devoted to modern ideas about treatment of patients with mild GP, its pathogenesis, clinical evidence and diagnostics, we can conclude about the diversity of this pathology and the lack of clear treatment algorithms, in particular conservative methods.

Thus, genital prolapse is a significant problem not only for women of perimenopausal or menopausal age, but also for those of reproductive age, both in the postpartum and in later life. The issues of conservative treatment of prolapse are still poorly understood and require further thorough study and improvement of the existing techniques. The detection of genital prolapse on the early stages of its development and timely conservative treatment can prevent the disease progression, minimize disease manifestations, especially in relation to the urinary bladder (incontinence) in most patients, and improve the life quality.

\section{REFERENCES}

1. Manuskiatti W., Fitzpatrick R.E., Goldman M.P. Longterm effectiveness and side effects of carbon dioxide laser resurfacing for photoaged facial skin. J Am Acad Dermatol. 1999; 40(3): 401-411.

2. Krizhanovsky A.N. Pathogenesis and early diagnosis of pelvic floor failure after physiological delivery: cand. med. sci. abstracts diss. M. 2012:25p. ( In Russia).

3. Rosenblum N. Pelvic organ prolaps: Considerations in surgical management. Annual Meeting Ana-heim. Course 10 EC.2007 . https:// www.ncbi.nlm.nih.gov/pmc/articles/PMC5610367/.

4. PietrzakW., Eppley B.Scientific foundations platelet rich plasma: biology and new technology. J. Craniofac. Surg. 2005;16(6):1043-1054.

5. Zheleznaya A.A., Tsvyashko T.I., Knurov I.Yu. et al. The use of platelet-rich autoplasma in obstetric and gynecological practice. Medical and social problems of the family. 2016;21(1):76. (in Ukrainian).

6. Xian L., Roy Chowdhury S., Bin Saim A., Bt Hj Idrus R.Concentrationdependent effect of platelet-rich plasma on keratinocyte and fibroblast wound healing. Cytotherapy. 2015;17(3):293-300.

7. Paoloni J., De Vos R., Hamilton B. et al. Platelet-Rich Plasma Treatment for Ligament Injuries. Clinical Journal of Sport Medicine. 2011;21(1):3745.

8. Everts P. Platelet-rich plasma and platelet gel: a review. JECT. 2006;38:174-187.

9. Makhmedzhanova F.N. Uroflowmetry with urinary dysfunction in women. Gynecology. 2013;15(1):76-78. (In Russian).

10. Gvozdev M.Y. Recurrent urinary incontinence. 2014; 3:80-87. (In Russian).

11. Rock J. A., Jones H. W., Rock J. A.Jr. TeLinde's Operative Gynecology. 11th ed. 2012; $1472 \mathrm{p}$.

12. Zvelto. 0. Laser principles. St. Petersburg: «Lan». 4th edition. 2008; 720 p. (In Russian).

13. Roberts T.L. 3rd, Pozner J.N. Lasers, facelifting, and the future. Clin Plast Surg 2000; 27(2): 293-299.

14. Schwartz R.J., Burns A.J., Rohrich R.J. et al. Long-term assessment of $\mathrm{CO2}$ facial laser resurfacing: aesthetic results and complications. Plast Reconstr Surg. 1999; 103(2): 592-601.

15. Weinstein C. Carbon dioxide laser resurfacing: longterm follow up in 2,123 patients. Clin Plast Surg. 1998; 25(1): 109-130.

16. Bernstein L.J., Kauvar A.N., Grossman M.C., Geronemus R.G. The shortand long-term side effects ofcarbon dioxide laser resurfacing. Dermatol Surg. 1997; 23(7): 519-525.

17. Palacios S., Castelo-Branco C., Currie H. et al. Update on management of genitourinary syndrome of menopause: A practical guide. Maturitas. 2015;82(3):308-313. https://doi.org/10.1016/j.maturitas.2015.07.020.

18. Apolikhina I.A., Gorbunova E.A., Odinokova V.A. Minimally invasive innovative laser technology in gynecological practice. Obstetrics and gynecology. 2014; 11: 17-22. (In Russian).

19. Arany P.R., Nayak R.S., Hallikerimath S. et al. Activation of latent TGFbeta1 by lowpower laser in vitro correlates with increased TGF-beta1 levels in laser-enhanced oral wound healing. Wound Repair Regen. 2007; 15(6): 866-874.

20. Hantash B.M., Bedi V.P., Kapadia B. et al. In vivo histological evaluation of a novel ablative fractional resurfacing device. Lasers Surg Med. 2007; 39(2): 96-107. 
21. Ravanti L., Kähäri V.M. Matrix metalloproteinases in wound repair (review). Int J Mol Med. 2000; 6(4): 391-407.

22. Zerbinati N., Serati M., Origoni M. et al. Microscopic and ultrastructural modifications of postmenopausal atrophic vaginal mucosa after fractional carbon dioxide laser treatment. Lasers in medical science. 2015;30(1):429-436.

23. Gallucci R.M., Lee E.G., Tomasek J.J. IL-6 modulates alpha-smooth muscle actin expression in dermal fibroblasts from IL-6-deficient mice. JInvest Dermatol. 2006; 126(3): 561-568. http://dx.doi.org/10.1038/ sj.jid.5700109.54.

24. Haisa M., Okochi H., Grotendorst G.R. Elevated levels of PDGF alpha receptors in keloid fibroblasts contribute to an enhanced response to PDGF. J Invest Dermatol. 1994; 103(4): 560-563.

25. Kumar S., Millis A.J., Baglioni C. Expression of interleukin 1-inducible genes and production of interleukin 1by aging human fibroblasts. Proc Natl Acad Sci USA. 1992; 89(10): 4683-4687. http://dx.doi. org/10.1073/pnas.89.10.4683.

26. Orringer J.S., Kang S., Johnson T.M. et al. Connective tissue remodeling induced by carbon dioxide laser resurfacing of photodamaged human skin. Arch Dermatol. 2004; 140(11): 1326-1332. http://dx.doi. org/10.1001/archderm. 140.11.1326.

27. Manstein D., Herron G.S., Sink R.K. et al. Fractional photothermolysis: a new concept for cutaneous remodeling using microscopic patterns of thermal injury. Lasers Surg Med. 2004; 34(5): 426-438. http://dx.doi. org/10.1002/lsm.20048.

\section{ORCID and contributionship:}

Kirill V. Chayka: 0000-0003-3518-1780 E,F

Yulia V. Lavrenuik: 0000-0003-0384-0243 ${ }^{\text {A,B,D }}$

\section{Conflict of interest:}

The Authors declare no conflict of interest

\section{CORRESPONDING AUTHOR}

Yulia V. Lavrenuik

Kyiv City reproductive and perinatal medicine Center

16 Heroes of Stalingrad avenue, 04210 Kyiv, Ukraine

tel: +380992204691

e-mail: Lavrenjuk-julja1987@ukr.net

Received: 18.04 .2020

Accepted: 11.11 .2020

A - Work concept and design, B - Data collection and analysis, C - Responsibility for statistical analysis,

D-Writing the article, $\mathbf{E}$-Critical review, $\mathbf{F}$ - Final approval of the article 


\title{
V INTERNATIONAL CONFERENCE ON MENTAL HEALTH CARE \\ "MENTAL HEALTH: GLOBAL CHALLENGES OF XXI CENTURY" \\ ARGIGIENTO, SICILY, ITALY \\ OCTOBER 21-23, 2021
}

\begin{abstract}
Mental Health Care (MHC) in the contemporary world has become a global problem with a number of negative consequences. According to the World Health Organization (WHO), mental and behavioural disorders are extremely common and affect up to $25 \%$ of all people in different periods of their lives. The WHO notes that in the future, given the ageing population and worsening social problems, the number of MHC cases will increase considerably.

Simultaneously, each country in the world faces significant hindrances in both sociopsychological and economic aspects of the MHC system. No country has yet been able to completely solve this problem. This creates an urgent need in joint efforts towards searching for solutions of common problems.
\end{abstract}

\section{Main objectives:}

- to attract researchers' and policy-makers' attention to MHC urgent problems

- to provide a platform for the exchange of ideas and development of (non)-academic MHC researchers, practitioners and policy-makers networks

- to promote high quality research on $\mathrm{MH}$ in developing and in-transition countries

- to investigate transdisciplinary and multicultural solutions of MHC specific issues

\section{Topics:}

- MHC systems in the context of global social challenges

- Management, organisation and treatment of Mental Health Issues support

- Specific issues of MHC: child neuro-psychiatry; support for disabled and elderly people; MHC in rural areas; addictive behaviour

- Inter- and trans-disciplinary approach to Global Mental Health issues

\section{Fields covered:}

Health, Medicine, Social Science, Psychology, Education, Economic, Law, Counseling, Inter- and Multi-disciplinary studies

\section{OFFICIAL INFORMATION}

The information about the conference is available on official website of the Conference: 